ever, Gosden realized that he could not write about the physiology of reproduction and menopause without also discussing the science of evolution and aging. Hence the subtitle of this book, Science, Sex and Aging. The author states in his preface that this book is 'written for everyone who is curious about aging of the body' and that his writing style aims to be "comprehensible rather than comprehensive." I think he has achieved that goal.

The first half of this easy-to-read book focuses on aging, but starts with a chapter about the "mating madness" of a short-lived, brown marsupial shrew, native to Australia. This intriguing animal, which mates once and then seems to undergo programmed aging and death, serves as a fascinating example of the clear relationship between reproduction and mortality. Gosden outlines the importance of hormones in orchestrating these events and gives examples of plants and other animals, such as the salmon, with biological clocks regulating them. Chapters 2-4 describe why different animals age differently, how some live much longer than others, how body and brain size relate to longevity and how most species show a gender gap in longevity. Physiological decline and the major diseases of aging are discussed, and the utility of biomarkers to assess rates of aging is presented. Considerable attention is given to the role of metabolism as related to rates of aging, and an excellent account of free radicals as causes of and antioxidants as protectors against aging is presented. The importance of heredity is introduced and arguments for and against the somatic mutation theory of aging are outlined. Hayflick's contributions to gerontology - that cells have a finite number of divisions - are discussed and up-to-date information on death genes, apoptosis and genes that promote longevity is introduced.

Chapter 5, The Great Trade-Off, is a well-written summary of what evolutionary biologists like Wallace, Weismann, Medawar and Williams have concluded about the evolution of aging, or senescence. Whether natural selection favors behavior that is good for the group or whether the individual is the supreme unit of selection is argued. The idea that natural selection fails to oppose late-acting bad genes is introduced, and the trade-offs between reproduction and survival are described. The importance of recent experiments by Mike Rose, who extended the maximum life span of fruit flies through selective breeding, closes this part of the book.

The second half of the book focuses primarily on changes that occur in the human male and female reproductive systems. Chapter 6 gives the reader an appreciation for the past and how Charles Edouard Brown-Sequard, the father of endocrinology, laid the groundwork for subsequent 'rejuvenators' to begin gland grafting to prolong the life of the reproductive system and to slow the aging process. Chapter 7 gives an historical account of gland grafters of the early 1900s, while chapters 8-11 describe the purification and synthesis of hormones, particularly the estrogens, progesterone and testosterone. The pros and cons of 'the pill' are outlined and the benefits of hormone replacement therapy discussed. The 'meaning of menopause' seems to be a favorite topic of the author's, and he goes to some length to describe how the number of eggs in an ovary is re-

lated to onset of menopause. The role of pituitary hormones in regulating female cycles is described, leading to a discussion of sex and sexuality in later years. Findings from The Kinsey Report and the Masters and Johnson study are presented.

Chapter 10 is effective in explaining the importance of hormones in sexual development, growth and behavior, and how signs of aging such as balding and osteoporosis are related to steroids and their receptors. The next chapter describes the complexities of reproduction and its decreasing efficiency with age. New procedures in artificial insemination and in vitro fertilization are discussed. The final chapter, Brave New Age, looks toward the future and suggests how we might be able to slow the aging process through gene or hormone manipulation. Studies with growth hormone, DHEA and melatonin supplementation are presented and suggestions for freezing ovaries or testicular cells for later implantation are made. Many years of hormone research has gotten us to this point and now the age of molecular genetics will take us forward.

Cheating Time offers enjoyable and interesting reading. Gosden shares with us his interest in the history of science, enjoys quoting great scholars of the past and does a nice job of telling us about the remarkable advances that have been made in gerontology and reproductive biology over the past hundred years. I would recommend this book to non-scientist and scientist alike.

\section{Yellow Fever, Black Goddess}

\section{THE COEVOLUTION OF PEOPLE AND PLAGUES}

\section{by Christopher Wills Addison-Wesley Publishing Company, Inc. ISBN: 0-201-44235-3, \$24.00}

ReViewed by William TRAGER

Professor of Parasitology, The Rockefeller University, 1230 York Avenue, New York, New York 10021-6390, USA

Yellow Fever, Black Goddess is a readable book, evidently intended for a general audience. It has little to say about yellow fever, but a great deal to say about plague (the Black Death), cholera and other diarrheal diseases. Malaria and syphilis receive considerable attention and there is a thorough discussion of the AIDS epidemic as well. The emphasis throughout is on diseases in the tropics in the poor countries of the Third World. The author makes a strong case for the connection between overcrowding, poor sanitation, pollution and general stressing of the environment and the prevalence of infectious diseases.

The book contains a lot of interesting information, including some historical background, all conveyed in an informal, somewhat breezy style. Like a good teacher, Wills stops to explain things as he goes along. For example, near the beginning of the book he mentions the small but deadly outbreak of the so-called Four Corners virus in New Mexico. This virus was identified by application of the polymerase chain reaction (PCR) technique and Wills digresses for three pages to provide a lucid explanation of PCR. 


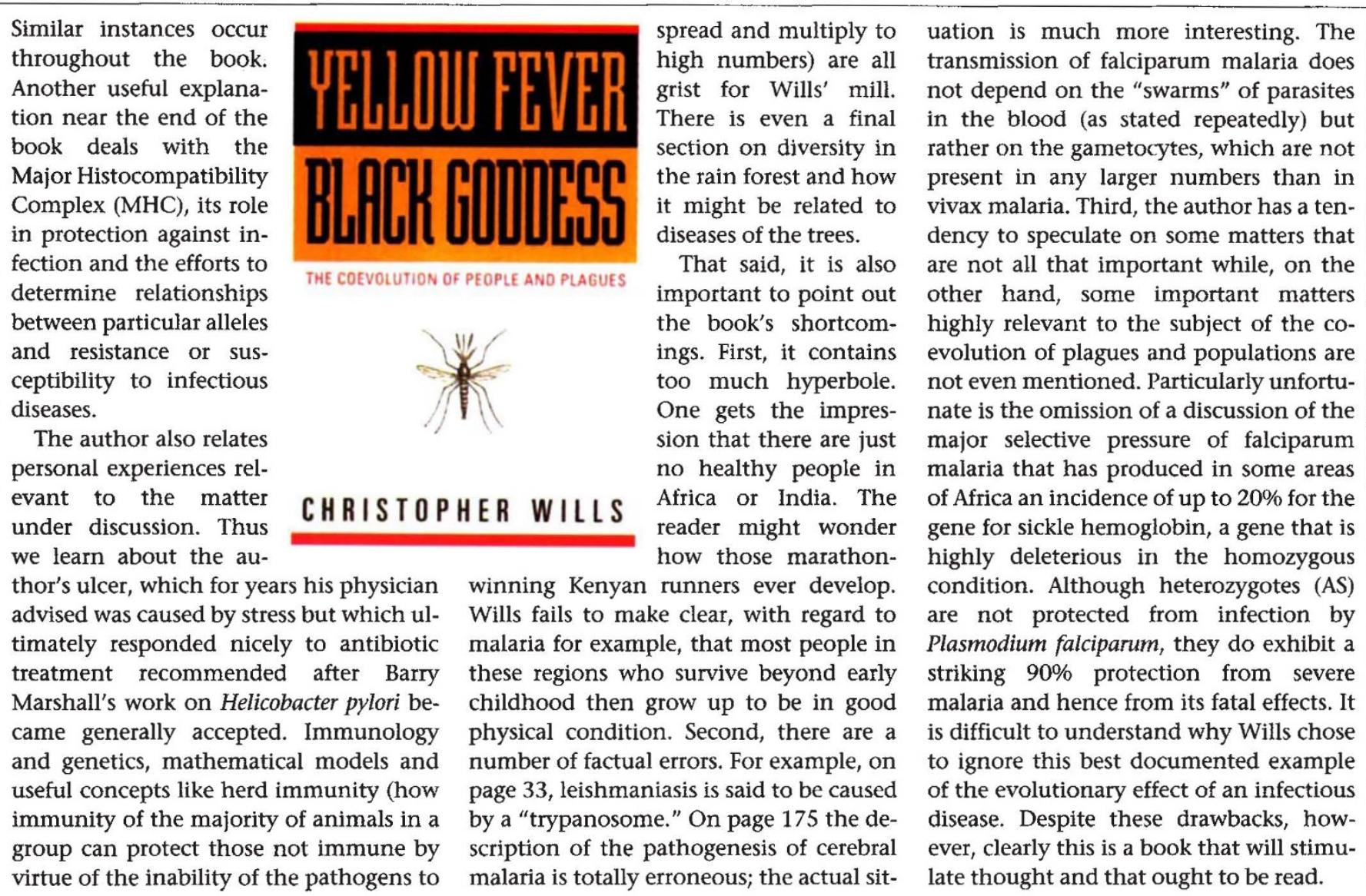
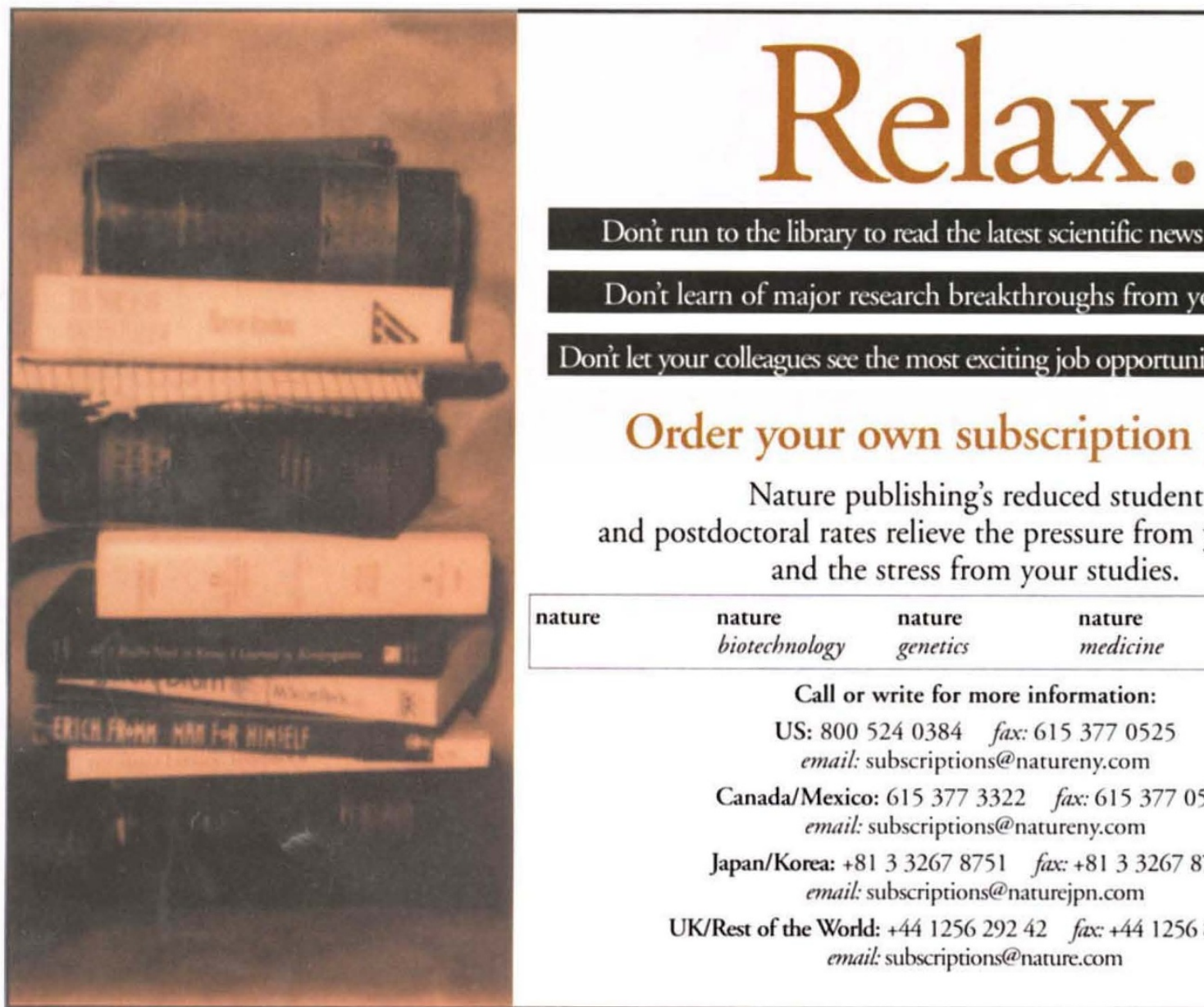

Don't run to the library to read the latest scientific news and opinions.

Don't learn of major research breakthroughs from your professor.

Don't let your colleagues see the most exciting job opportunities before you do.

\section{Order your own subscription today!}

Nature publishing's reduced student

and postdoctoral rates relieve the pressure from your pocket

and the stress from your studies.

\begin{tabular}{|c|c|c|c|c|}
\hline nature & $\begin{array}{l}\text { nature } \\
\text { biotechnology }\end{array}$ & $\begin{array}{l}\text { nature } \\
\text { genetics }\end{array}$ & $\begin{array}{l}\text { nature } \\
\text { medicine }\end{array}$ & $\begin{array}{l}\text { nature } \\
\text { structural biology }\end{array}$ \\
\hline
\end{tabular}

Call or write for more information:

US: 8005240384 fax: 6153770525

email: subscriptions@natureny.com

Canada/Mexico: 6153773322 fax: 6153770525

email: subscriptions@natureny.com

Japan/Korea: +81332678751 fax: +81332678746

email: subscriptions@naturejpn.com

UK/Rest of the World: +44125629242 fax: +44 1256842754

cmail: subscriptions@nature.com 